\title{
Interpersonal Problems in People with Bulimia Nervosa and the Role of Interpersonal Psychotherapy
}

\author{
Jon Arcelus ${ }^{1,2}$, Debbie Whight ${ }^{1}$ and Michelle Haslam ${ }^{2}$ \\ ${ }^{1}$ Leicestershire Partnership NHS Trust, Leicester, \\ ${ }^{2}$ Loughborough University Centre for Research into Eating Disorders (LUCRED), \\ Loughborough University, \\ UK
}

\section{Introduction}

The term 'interpersonal' encompasses not only the patterns of interaction between the individual and significant others, but also the process by which these interactions are internalised and form part of the self-image (Sullivan, 1953). Interpersonal functioning is considered crucial to good mental health. According to Klinger (1977), when people are asked what makes their lives meaningful, most will mention their close relationships with others. Being involved in secure and fulfilling relationships is perceived by most individuals as critical to wellbeing and happiness (Berscheid \& Peplau, 1983).

Maladaptive interpersonal functioning is considered central to several psychiatric disorders, such as depression (e.g. Petty, et al, 2004), anxiety (e.g. Montgomery et al, 1991), schizophrenia (e.g. Sullivan \& Allen, 1999) and autistic spectrum disorders (e.g. Travis \& Sigman, 1998). Interpersonal skill deficits may cause vulnerability to developing mental health problems and may also play a role in maintaining it. This is the chicken and egg question: are interpersonal problems vulnerability factors for the development of a psychiatric disorder or are they the result of this disorder?

\section{Interpersonal problems and eating disorders}

Considering that unhealthy interpersonal functioning is central to several mental health problems, it is not surprising that evidence suggests this is also the case in eating disorders. Walsh et al (1985) demonstrated a high frequency of affective disorder, particularly major depression, among patients with bulimia nervosa (BN), which may explain the strong correlation found between this disorder (BN) and interpersonal problems (Hopwood et al, 2007). Research in this area have found that people suffering from BN were more likely to display domineering, vindictive, cold, socially avoidant, non-assertive, exploitable, overly nurturing, or intrusive characteristics than non-BN (Hopwood et al, 2007).

Social support and social networks have also been studied in people with BN. Grisset and Norvell (1992) found that people with BN reported receiving less emotional and practical support from friends and family. They argue that this inadequate support creates a 
vulnerability towards developing eating disorder symptoms as a coping mechanism. Eating disordered individuals are also less likely to utilise support from others, particularly due to a negative attitude towards emotional expression (Meyer et al 2010). In terms of relationship satisfaction, women with eating problems report more discomfort with closeness and have been described to fear intimacy with a partner (Evans \& Wertheim, 1998; Pruitt et al, 1992).

Therefore in view of the correlation between interpersonal problems and $\mathrm{BN}$, it is not surprising that a specific therapy aimed at helping patients with interpersonal problems (IPT) was considered as a treatment of this disorder.

\section{The development of Interpersonal Psychotherapy (IPT)}

IPT was developed for the treatment of depression and originates from theories in which interpersonal functioning is recognised to be a critical component of psychological wellbeing. The work of 1930's psychiatrist Harry Sullivan first suggested that patients' mental health was related to their interpersonal contact with others. Challenging Freud's psychosexual theory, Sullivan emphasized the role of interpersonal relations, society and culture as the primary determinants of mental health (Sullivan, 1968). Sullivan's work was further developed by Gerald Klerman and Myrna Weissman in the 1980's, who studied depression treatments using the interpersonal approach. Whilst studying the efficacy of antidepressants, alone or paired with psychotherapy, it was found that 'high contact' counselling was effective, leading to the further development of the therapy which was renamed interpersonal psychotherapy (Klerman et al, 1984). These positive results led to the inclusion of IPT in the NIMH Treatment of Depression Collaborative Research Program, which compared this therapy with antidepressants, placebo and Cognitive Behavioural Therapy (CBT) for depression (Elkin et al., 1989). As a part of this study the original IPT manual, Interpersonal Psychotherapy for Depression, was published as a manual for the research project (Klerman et al, 1984). Patients in all conditions showed significant reduction in depressive symptoms and improvement in functioning, those having the antidepressant Imipramine plus clinical management generally doing best, the two psychotherapies second best, and placebo plus clinical management worst. There was no significant difference between the two psychotherapies.

Since then, there have been several systematic reviews of studies investigating the efficacy of IPT for depression (Jarrett \& Rush, 1994; Klerman, 1994; Feijo de Mello et al., 2005). They concluded that IPT was superior to placebo in nine of thirteen studies and better than CBT overall. However IPT plus medication was no more effective than medication alone. The researchers also found that several factors were associated with good therapy outcome, including the ability to engage in more than one perspective and to take responsibility for actions, empathy for others, a desire to change, good communication skills, and a sense of cooperation and willingness to engage with the therapist.

Feske et al (1998) examined predictors of outcome in 134 female patients with major depression, and found that those who did not improve experienced higher levels of anxiety and were also more likely to meet diagnostic criteria for panic disorder. In addition, they found that poor outcome was associated with greater vocational impairment, longer duration of episode, more severe illness, and surprisingly, lower levels of social impairment. Other authors have found that despite comparable efficacy between IPT and CBT, IPT was more affected by personality traits and therefore less suitable for those with personality disorders (Joyce et al. 2007). 


\section{The development of IPT for Bulimia Nervosa}

Since the conception of IPT, the original manual has been updated (Weissman et al, 2000; Weissman et al, 2007) and several manuals have been written concerning modifications of IPT, including those for depressed adolescents (Mufson et al, 2004), the elderly (Hinrichsen \& Clougherty, 2006), perinatal women (Weissman et al, 2000), HIV patients (Pergami et al 1999), bipolar disorder (Frank, 2005), social phobia (Hoffart et al., 2007), dysthymic disorder (Markowitz, 1998) and finally bulimia nervosa (IPT-BN; Fairburn, 1993).

IPT-BN was not developed systematically through an adaptation from IPT for depression, but instead was discovered to be effective when used as a control treatment for CBT during a randomised controlled trial for individuals with BN (Fairburn et al., 1991). IPT was not adapted specifically for $\mathrm{BN}$ in the treatment trial, and beyond limited initial psychoeducation, eating problems were not addressed during the treatment. It was hypothesised that as IPT shared some non-specific factors with CBT, its inclusion in the trial would highlight the benefits of cognitive behavioural techniques in CBT that were not present in IPT. However, while CBT was considered most effective, IPT also resulted in the improvement of eating disorder symptoms. This discovery led to the further development of IPT-BN as a viable treatment option, and it was manualised in 1993 (Fairburn, 1993).

Since its conception, IPT has been compared to CBT, the current treatment of choice, with equally positive results in both individual and group settings (Fairburn, 1997; Fairburn et al, 1993; Fairburn et al., 1991; Fairburn et al, 2000; Roth \& Ross, 1988; Wilfley et al., 2003; Wilfley et al., 1993). Agras et al (2000) found that CBT was superior to IPT at the end of treatment however there was no significant difference between the two treatments at one year follow-up. Based on these findings, the NICE guidelines for eating disorders in the UK (NICE, 2004) recommends IPT as an alternative to CBT for the treatment of BN but patients should be informed that it could take longer that CBT to achieve comparable results.

The efficacy of IPT in patients with BN has been explained by Fairburn (1997). He claimed that IPT might work through several mechanisms. Firstly, IPT helps patients to overcome well established interpersonal difficulties, for example when focusing on interpersonal 'role transitions' this can be helpful for those patients who have missed out on the interpersonal challenges of early adulthood as a result of their eating disorder. Secondly, IPT can open up new interpersonal opportunities and as a result patients learn to rely more on interpersonal functioning for self evaluation instead of focusing wholly on eating, weight and shape. Finally, IPT gives patients a sense that they are capable of influencing their interpersonal lives and therefore may lessen their need to control their eating, weight and shape.

\section{Modification of IPT-BN}

The IPT Team in Leicester (UK) adapted IPT-BN further by bringing back the original components of IPT (psycho-education, directive techniques, problem solving, modelling, role play and symptom review) and modifying the treatment for individual with $\mathrm{BN}$ where the eating disorders problems are taken into consideration. Although they have been using this model of treatment for BN for more than 15 years, only recently they have manualised it (Whight et al, 2010). This new modified version of IPT for BN is called IPT-BNm in this chapter to differentiate it from the IPT-BN developed by Fairburn.

IPT-BNm uses a time frame of 12-20 weekly sessions. The usual number of sessions is 16 , which roughly breaks down into three areas: 4 assessment sessions, 10 middle sessions and 2 termination sessions. There is also a pre-treatment session (Session 0) where the patient 
and therapist agree goals for treatment and the model is explained. Therapy may be extended to up to 20 sessions if this is felt to be clinically appropriate, however this should be agreed with the patient close to the start of therapy and not towards the end of therapy as this can affect the potency of the termination sessions. The number of sessions may also be reduced if felt to be appropriate for the patient, but again should be agreed near the beginning of treatment.

\subsection{Overview of IPT-BNm}

\subsubsection{Early sessions: sessions $\mathbf{0 - 4}$}

Broadly speaking the initial sessions are as detailed in the original IPT manual for depression (Klerman et al 1984) but specific for eating disorders. The aims of these sessions are to get a clear picture of the current problems along with a history of previous difficulties and interpersonal events. This enables the therapist and patient to identify areas of current difficulty, agree realistic treatment goals and to establish a focus for therapy. Areas for assessment include mood, interpersonal network, historical events (timeline) and eating disorder symptomatology. The main task of the therapist is to help the patient gain some understanding of the inter-relatedness of their presenting difficulties and to establish a specific focus for treatment dependent on their individual situation. As a part of this process and what makes this therapy specific for patients with $\mathrm{BN}$ is the use of psycho education related to eating. Throughout the therapy patients will be encouraged to complete food diaries that will be used to regulate patients eating. Psycho-education is a fundamental part of therapy.

By the end of session 4 the therapist will have a good understanding of whether or not the patient is able to work within the IPT model. The model is not suitable for everybody therefore if IPT is felt to be inappropriate other treatment options may be considered with the patient. IPT is primarily an outpatient treatment, but the early sessions could be started as an inpatient if needed, with the understanding that the patient would be discharged before treatment ended. This would enable them to practise skills between sessions and to build their interpersonal networks, which may be more difficult to achieve as an inpatient.

\subsubsection{The role of the therapist}

The therapist needs to engage the patient in therapy. A non-pejorative approach and an empathic understanding of the patient's distress can be crucial in gaining the trust - and therefore the commitment - of the patient. The therapist also needs to be clear about the boundaries of therapy. The sessions are weekly and commitment to regular sessions is an important part of therapy. Weekly therapy helps to maintain the intensity of the treatment whilst also giving the patient time to practice tasks between sessions. It is helpful to count down each session, letting the patient know where they are in therapy and how many sessions are left - for example "We are on session 2 . We have 14 sessions left". This helps to start the process of termination but also emphasises the short-term nature of the therapy. This in turn acts as an incentive for the patient to make changes in therapy as they are aware of what time they have got from the beginning. It is also important for the therapist to stick to the boundaries of therapy - start on time, finish on time and always state the date and time of the next appointment at the end of each session. It can be very helpful to have the dates of all the sessions agreed as this avoids any confusion.

The role of the therapist in the early sessions is of active participation. The therapist is tasked to gather information on the patient's history, presenting problems, interpersonal 
world and expectations of treatment. He/She is also helping the patient to make links between their difficulties and their interpersonal issues. This can be difficult, particularly as secrecy is so often an issue with patients with $\mathrm{BN}$.

\subsubsection{The role of the patient}

The patient needs to be actively involved in therapy throughout. The more they put into therapy the more they will get out of it. Initially the patient should be willing to share their difficulties and be able to listen to the therapist, working with them at making sense of the current difficulties and identifying realistic goals. The patient needs to be able to attend all planned sessions and to focus on any agreed tasks between sessions. Patients are also expected to track their symptoms each week and to bring to the session any relevant information about the agreed focus area. Changes in symptoms can often be markers of interpersonal events, so helping to link these changes to the agreed interpersonal focus area is an important skill for the patient to master.

\subsubsection{Interpersonal focus area}

The main task of session 4 is in helping the patient to choose a focus area to work on during the middle sessions of therapy. As in the original manual for IPT for depression, there are 4 clear focus areas:

- Interpersonal Role Disputes: Difficulties occur when the patient has non-reciprocal expectations from a significant other. This could be an overt or covert dispute and often there is a pattern of difficult relationships around the patient. It is important to focus on one key relationship that is current and where the patient feels that change is possible.

- Interpersonal Role Transitions: Difficulties occur when the patient has difficulty adjusting or adapting to changes in their life. This could be changes at work, in living situation, in relationships, in financial status or any other area. What is key is that the patient has not adapted well to the changes and this is linked to their illness onset or deterioration.

- Interpersonal Deficits: Difficulties occur when patients had problems making or sustaining relationships with people. There are often repeated patterns of broken or failed relationships and the patient may be socially isolated. The patient may be highly sensitive to their difficulties so it can be very helpful to use role play in the session to help them practice new skills.

- Complicated Bereavement: Difficulties can occur when a patient is not able to resolve the death of a significant figure. This is often a partner or a family member, but can be the death of a friend or even a pet. The key feature is that the patient is not able to complete a grieving process and this impacts on their eating disorder and mood. The nature of the attachment with the deceased is an important consideration when considering grief as a focus area.

The task of the therapist is to find the most appropriate focus with their patient. All the information gained so far is assessed by the therapist, who by session 4 usually has an idea of what interpersonal issues are central to the patient's problems. IPT does not seek to understand the dynamics behind the eating disorder/depression but rather to help the patient make changes to their life now. The formulation for IPT is therefore simple, pragmatic and collaborative. Using the patient's words and a summary of the identified problem areas that have been highlighted over the previous 3 sessions, the therapist may suggest an area to focus on in therapy. 


\subsubsection{Middle sessions: Sessions 5-14}

The middle sessions follow a similar format to each other, with the patient being asked to bring in their own material from the week to work within therapy. The therapist helps the patient to link the changes in the symptoms to the focus area, then works with the patient at active problem solving, contingency planning or practising new skills as appropriate.

The therapist maintains a hopeful and realistic stance on the patient's ability to make changes and to recover. All attempts at change should be praised as it can help to enhance the patient's feelings of self worth and their confidence at trying something new. It also helps to keep them engaged in therapy and to feel that the therapist is on their side working with them. This also needs to be balanced with the patient's capacity to change so it is important to be realistic.

All patients will have some difficulties with changing their way of eating, bingeing and vomiting. It is important to review the symptoms each week to maintain the focus and to identify change, but lack of change is also an issue. Some patients find it more difficult to make changes to their eating patterns and can really struggle to do things differently. It is part of the therapist's role to continue to encourage and support them whilst also being open and frank about change. Because the therapy is time limited this helps to motivate people to change, but lack of progress should not be ignored. Enquiring about what difficulties the patient is experiencing and helping them to develop problem-solving strategies to enhance their abilities to put therapy into practise can enable the patient to feel more attended to and can address feelings of having failed or worthlessness. As these can be key features of both eating disorders and depression they are important issues to address. Feeling attended to and supported can help the patient to stay engaged in therapy.

Half way through IPT (session 8) therapy is reviewed. This review is planned from the beginning. It is highlighted as a time to see how things have progressed thus far, ensuring that the right focus area is being worked on and allowing room for change if needed by the patient or the therapist.

\subsubsection{Termination sessions: $\mathbf{1 5 - 1 6}$}

The end of therapy should not come as a surprise to the patient; the therapist will have been counting down sessions and will have planned the dates of the final session with the patient. However it can still can come as a shock. The final 2 sessions are explicitly about ending therapy, about recognising and maintaining changes made, acknowledging that which has not changed and exploring feelings about ending. This can feel very positive for a patient who has recovered or more anxiety provoking for one who has not. It is important to end after the agreed number of sessions.

\subsection{Efficacy of IPT -BN(m)}

Arcelus et al (2009) conducted a case series evaluation of 59 patients and found that by the middle of therapy there had been a significant reduction in eating disordered cognitions and behaviours, alongside an improvement in interpersonal functioning and depressive symptoms. The authors found that although patients did improve significantly after eight sessions, their symptomatology did not continue to improve in the same way within the last eight sessions. This may suggest that there was something in the first sessions that facilitates change, which is lost in the last sessions. This could be explained by the impetus of the initial sessions; targeting symptoms, an opportunity to change and exploring the 
interpersonal context and maintenance of the eating disorder. Perhaps this sets the ground for facilitating change and the setting of interpersonal goals can instill hope. Although the use of a case series was considered appropriate given the exploratory nature of the study, it is important to remember that these preliminary findings should be interpreted within the limitations of a case series design. Although there is incidental evidence from clinicians and patients of the effectiveness of this modified version of IPT for BN, there is a lack of research evidence which can only been achieved by a control Trial.

\section{New modifications of IPT for patients with eating disorders}

In recent months, a new theoretical model of IPT for eating disorders has been proposed (Reiger et al., 2010). This model suggests that eating disorders are triggered by negative feedback regarding an individual's social worth due to its negative effect on self-esteem and associated mood. Eating disordered behaviours often begin because of this negative social evaluation, and over time such behaviours may become a more reliable source of self esteem and mood regulation than social interactions. The aim of IPT then is to help the patient to develop positive, healthy relationships, which replace the eating disorder in the attainment of positive esteem and affect. This newly proposed model also includes the monitoring of eating disorder symptoms and other elements, which were taken out of the original IPT-BN to make it comparable with CBT. However, this new therapeutic model has not yet been supported by empirical studies and does not differentiate between the treatment of anorexic and bulimic disorders.

\section{Conclusion}

Interpersonal difficulties are both vulnerability factors and consequences of several psychiatric disorders, including Bulimia Nervosa. Over the last several years a growing number of research studies have demonstrated the efficacy of IPT as a treatment for several conditions. Within the field of eating disorders, IPT has been shown to be effective for patients with BN, although it appears to work slower than CBT. In order to make this treatment more effective several authors in different countries have modified this treatment further. In spite of the modification that IPT has gone through, the core elements of the therapy have been retained. Throughout IPT, therapists aim to help patients to identify the interpersonal difficulties maintaining the eating disorders symptoms in order to work through them. Although IPT has been used successfully over a number of years, research evidence for the new modified versions is still required.

\section{Acknowledgement}

We would like to acknowledge the IPT team in Leicester: Mrs Lesley McGrain, Ms Lesley Meadows, Dr Jonathan Baggott and Mr Chris Langham.

\section{References}

Agras, W.S., Walsh, T., Fairburn, C.G., Wilson, G.T., and Kraemer, H.C (2000) A multicenter comparison of cognitive-behavioral therapy and interpersonal psychotherapy for bulimia nervosa. Archives of General Psychiatry, 57, 5, 459-66 
Arcelus, J., Whight, D., Langham, C., Baggott, J., McGrain, L., Meadows. L., \& Meyer, C. (2009). A case series evaluation of a modified version of interpersonal psychotherapy (IPT) for the treatment of bulimic eating disorders: A pilot study. European Eating Disorders Review, 17, 260-268.

Berscheid, E., \& Peplau, L. A. (1983). The emerging science of relationships. In Close relationships, H. H. Kelley, E. Berscheid, A. Christensen, J. H. Harvey, T. L. Huston, G. Levinger et al. (Eds.) pp. (1-19), W.H.Freeman \& Co Ltd, 978-0716714439, New York.

Elkin, L., Shea, T., Watkins, J. T., Imber, S. D., Sotsky, S. M., Collins, J. F. (1989). National Institute of Mental Health Treatment of Depression Collaborative Research Program: General effectiveness of treatments. Archives of General Psychiatry, 46, 971982.

Evans, L., \& Wertheim, E. H. (1998). Intimacy patterns and relationship satisfaction of women with eating problems and the mediating effects of depression, trait anxiety and social anxiety. Journal of Psychosomatic Research, 44, 355-365.

Fairburn, C.G. (1993). Interpersonal psychotherapy for bulimia nervosa. In New applications of interpersonal therapy, G.L. Klerman \& M.M. Weissman (Eds.), pp. (278-294), American Psychiatric Press, 978-0880485111, Washington DC

Fairburn, C.G. (1997). Interpersonal psychotherapy for bulimia nervosa. In Handbook of treatment for eating disorders, D.M. Garner \& P.E. Garfinkel (Eds.), pp. (278-294). Guilford Press, 978-1572301863, New York.

Fairburn, C. G., Wilson, G. T., \& Kraemer, H. C. (2000). A multicenter comparison of cognitive-behavioural therapy and interpersonal psychotherapy for bulimia nervosa. Archives of General Psychiatry, 5, 459-466.

Fairburn, C. G., Jones, R., Peveler, R. C., Carr, S. J., Solomon, R. A., O'Connor, M. E., Burton, J., \& Hope, R. A. (1991). Three psychological treatments for bulimia nervosa: A comparative trial. Archives of General Psychiatry, 48, 463-469.

Fairburn, C. G., Jones, R., Peveler, R. C., Hope, R. A., \& O'Connor, M. (1993). Psychotherapy and bulimia nervosa: longer term effects of interpersonal psychotherapy, behavior therapy and cognitive behaviour therapy. Archives of General Psychiatry, 50, 419-428.

Feijo de Mello, M., de Jesus Mari, J., Bacaltchuk, J., Verdeli, H., \& Neugebauer, R. (2005). A systematic review of research findings on the efficacy of interpersonal therapy for depressive disorders. European Archives of Psychiatry and Clinical Neuroscience, 255, 75-82.

Feske, U., Frank, E., Kupfer, D. J., Shear, K., Weaver, E. (1998). Anxiety as a predictor of response to Interpersonal psychotherapy for recurrent major depression: an exploratory investigation. Depression and Anxiety, 8, 135-141.

Frank, E. (2005). Treating Bipolar Disorder: A Clinician's Guide to Interpersonal and Social Rhythm Therapy, Guilford, 978-1593854652, New York

Grissett, N.I. and Norvell, N.K. (1992). Perceived social support, social skills, and quality of relationships in bulimic women. Journal of Consulting Clinical Psychology, 60, 293299.

Hinrichsen, G.A., \& Clougherty, K.F. (2006). Interpersonal psychotherapy for depressed older adults, American Psychological Association, 978-1591473619, Washington, DC 
Hoffart, A., Abrahamsen, G., Bonsaksen, T., Borge, F.M., Ramstad, R., Lipsitz, J., \& Markowitz, J.C. (2007). A Residential Interpersonal Treatment for Social Phobia. New York, Nova Science Publishers Inc.

Hopwood, C., Clarke, A., Perez, M. (2007). Pathoplasticity of Bulimic Features and Interpersonal Problems. International Journal of Eating Disorders, 40, 652 - 658.

Jarrett, R. B., \& Rush, A. J. (1994). Short term psychotherapy of depressive disorders: current status and future directions. Psychiatry, 57, 115-132.

Joyce, P. R., McKenzie, J. M., Carter, J. D., Rae, A. M. Luty, S. E., Frampton, C. M. A., Mulder, R. T. (2007). Temperament, character and personality disorders as predictors of response to interpersonal psychotherapy and cognitive-behavioural therapy for depression. The British Journal of Psychiatry, 190, 503-508.

Klerman, G.L., DiMascio, A., Weissman, M.M., Prusoff, B.A., \& Paykel, E.S. (1974). Treatment of depression by drugs and psychotherapy. American Journal of Psychiatry, 131, 186-191.

Klerman, G.L.,Weissman, M.M., Rounsaville, B.J., \& Chevron, E.S. (1984). Interpersonal psychotherapy of depression. Basic Books, 978-1568213507, New York.

Klinger, E. (1977). Meaning and void: Inner experience and the incentives in peoples lives. University of Minnesota Press, Minnesota

Markowitz, J. C. (1998). Interpersonal Psychotherapy for Dysthymic Disorder. American Psychiatric Press, 978-0880489140, Washington, D.C.

Meyer, C., Leung, N., Barry, L., \& De Feo, D. (2010). Brief Report. Emotion and Eating Psychopathology: Links with Attitudes Toward Emotional Expression Among Young Women. International Journal of Eating Disorders, 43, 2, 187-189

Montgomery, R. L., Haemmerlie, F. M., \& Edwards, M. (1991). Social, personal, and interpersonal deficits in socially anxious people. Journal of social behaviour and personality, 6, 859-872.

Mufson, L., Dorta, K.P., Moreau, D., \& Weissman, M.M. (2004). Interpersonal Psychotherapy for Depressed Adolescents, Guildford press, 978-1609182267, New York.

National Institute of Clinical Excellence (NICE) (2004). Core interventions in the treatment and management of anorexia nervosa, bulimia nervosa and related eating disorders. British Psychological Society/RCPsych Publications, 978-1854333988, London

Petty, S. C., Sachs-Ericsson, N., \& Joiner, T. E. (2004) Interpersonal functioning deficits: temporary or stable characteristics of depressed individuals? Journal of Affective Disorders, 81, 115-122.

Pruitt, J.A., Kappius, RE. \& Gorman, P.W. (1992). Bulimia and fear of intimacy. Journal of Clinical Psvchology, 48, 472-476.

Reiger, E., Van Buren, D. J., Bishop, M., Tanofsky-Kraff, M., Welch, R., \& Wilfley, D.E. (2010). An eating disorder specific model of interpersonal psychotherapy (IPT-ED): causal pathways and treatment implications. Clinical Psychology Review, 4, 400-410.

Roth, D.M. \& Ross, D. R. (1988). Long-term cognitive-interpersonal group therapy for eating disorders. International Journal of Group Psychotherapy, 38, 491-510.

Sullivan, H. (1968). The interpersonal theory of psychiatry. W. W. Norton \& Company.

Sullivan, R. J., \& Allen, J. S. (1999).Social deficits associated with schizophrenia defined in terms of interpersonal Machiavellianism. Acta Psychiatrica Scandinavia, 99, 148- 54.

Travis, L. I., \& Sigman, M. (1998). Social deficits and interpersonal relationships in autism. Mental Retardation and Developmental Disabilities Research Reviews, 4, 65-72. 
Walsh, T., Roose, S. P., Glassman, A. H., Gladise, M., Sadik, C. (1985). Bulimia and Depression. Psychosomatic Medicine, 47, 123-131.

Weissman, M. M., Markowitz, J. C., \& Klerman, G. L. (2000). Comprehensive guide to interpersonal psychotherapy. Basic Books, 978-0465095667, New York.

Weissman, M. M., Markowitz, J. C., \& Klerman, G. L. (2007). Clinicians quick guide to interpersonal psychotherapy. Oxford University Press, 978-0195309416, USA.

Whight, D., McGrain, L., Langham, C., Baggott, J., Meadows, L. \& Arcelus, J. (2010). A new version of interpersonal psychotherapy for bulimic disorders. The manual, LPT, Retrieved from www.wix.com/leicesteript/ipt-leicester

Wilfley, D. E., Agras, W. S., Telch, C. F., Rossiter, E. M., Schneider, J. A., Cole, A.G., Sifford, L., \& Raeburn, S. D. (1993). Group cognitive-behavioral therapy and group interpersonal psychotherapy for the nonpurging bulimic individual: A controlled comparison. Journal of Consulting and Clinical Psychology, 61, 296-305.

Wilfley, D., Stein, R., \& Welch, R. (2003). Interpersonal Psychotherapy. In J. Treasure, U. Smith \& E. van Furth (2003). Handbook of eating disorders. John Wiley and Sons. 


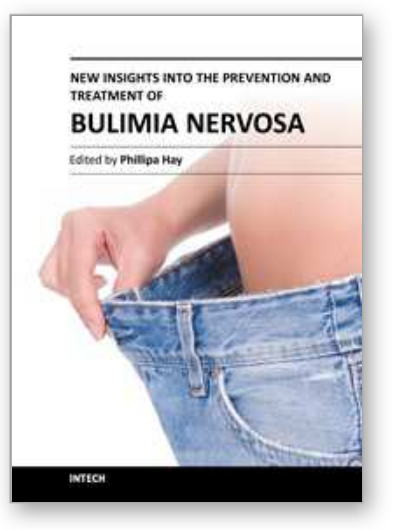

\author{
New Insights into the Prevention and Treatment of Bulimia Nervosa \\ Edited by Prof. Phillipa Hay
}

ISBN 978-953-307-767-3

Hard cover, 190 pages

Publisher InTech

Published online 03, October, 2011

Published in print edition October, 2011

Bulimia nervosa and eating disorders are common cause of distress and health related burden for young women and men. Despite major advances over the past three decades many patients come late to treatment and find that the therapy is incompletely addressed to the complex psychopathology and co-morbidities of the illness. The present book brings timely and contemporary understandings of bulimia nervosa to aid in current thinking regarding prevention and treatment. It will be read by therapists interested in enhancing their current approaches and those interested in earlier and more effective prevention and closing the gap between illness onset and accessing treatment. They will find practical guidance but also new ideas and ways of thinking about bulimia nervosa and the illness experience in this book.

\title{
How to reference
}

In order to correctly reference this scholarly work, feel free to copy and paste the following:

Jon Arcelus, Debbie Whight and Michelle Haslam (2011). Interpersonal Problems in People with Bulimia Nervosa and the Role of Interpersonal Psychotherapya, New Insights into the Prevention and Treatment of Bulimia Nervosa, Prof. Phillipa Hay (Ed.), ISBN: 978-953-307-767-3, InTech, Available from: http://www.intechopen.com/books/new-insights-into-the-prevention-and-treatment-of-bulimianervosa/interpersonal-problems-in-people-with-bulimia-nervosa-and-the-role-of-interpersonal-psychotherapya

\section{INTECH}

open science | open minds

\author{
InTech Europe \\ University Campus STeP Ri \\ Slavka Krautzeka 83/A \\ 51000 Rijeka, Croatia \\ Phone: +385 (51) 770447 \\ Fax: +385 (51) 686166 \\ www.intechopen.com
}

\author{
InTech China \\ Unit 405, Office Block, Hotel Equatorial Shanghai \\ No.65, Yan An Road (West), Shanghai, 200040, China \\ 中国上海市延安西路65号上海国际贵都大饭店办公楼 405 单元 \\ Phone: +86-21-62489820 \\ Fax: +86-21-62489821
}


(C) 2011 The Author(s). Licensee IntechOpen. This is an open access article distributed under the terms of the Creative Commons Attribution 3.0 License, which permits unrestricted use, distribution, and reproduction in any medium, provided the original work is properly cited. 